
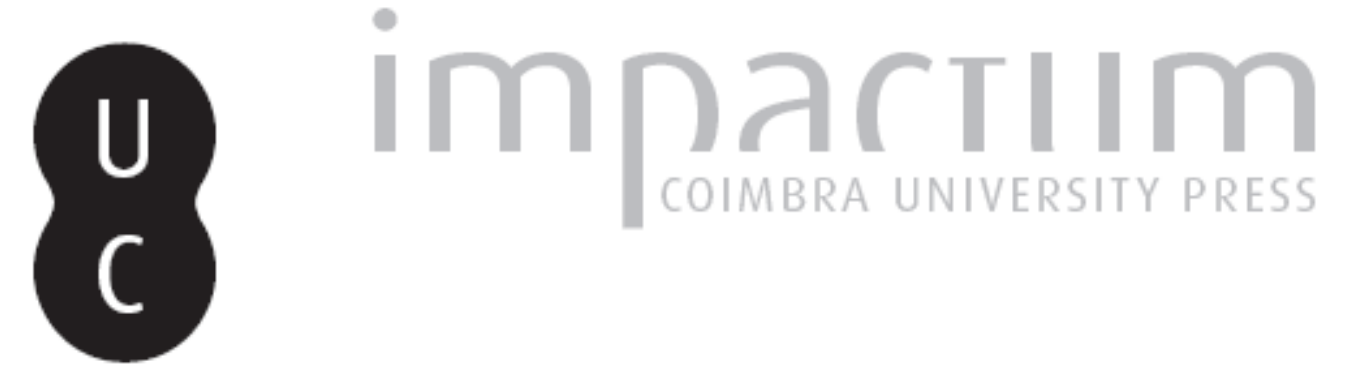

\title{
O visível e a visão no Manuscrito 2399 atribuído a Pedro da Fonseca: nota de investigação sobre o capítulo VII do livro II do comentário ao ‘De Anima' de Aristóteles
}

\author{
Autor(es): $\quad$ Camps, Maria da Conceição
}

Publicado por: Faculdade de Letras da Universidade de Coimbra, Instituto de Estudos

URL

persistente: URI:http://hdl.handle.net/10316.2/34104

DOI: $\quad$ DOI:http://dx.doi.org/10.14195/0872-0851_44_6

Accessed : $\quad$ 26-Apr-2023 13:40:16

A navegação consulta e descarregamento dos títulos inseridos nas Bibliotecas Digitais UC Digitalis, UC Pombalina e UC Impactum, pressupõem a aceitação plena e sem reservas dos Termos e Condições de Uso destas Bibliotecas Digitais, disponíveis em https://digitalis.uc.pt/pt-pt/termos.

Conforme exposto nos referidos Termos e Condições de Uso, o descarregamento de títulos de acesso restrito requer uma licença válida de autorização devendo o utilizador aceder ao(s) documento(s) a partir de um endereço de IP da instituição detentora da supramencionada licença.

Ao utilizador é apenas permitido o descarregamento para uso pessoal, pelo que o emprego do(s) título(s) descarregado(s) para outro fim, designadamente comercial, carece de autorização do respetivo autor ou editor da obra.

Na medida em que todas as obras da UC Digitalis se encontram protegidas pelo Código do Direito de Autor e Direitos Conexos e demais legislação aplicável, toda a cópia, parcial ou total, deste documento, nos casos em que é legalmente admitida, deverá conter ou fazer-se acompanhar por este aviso.

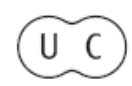




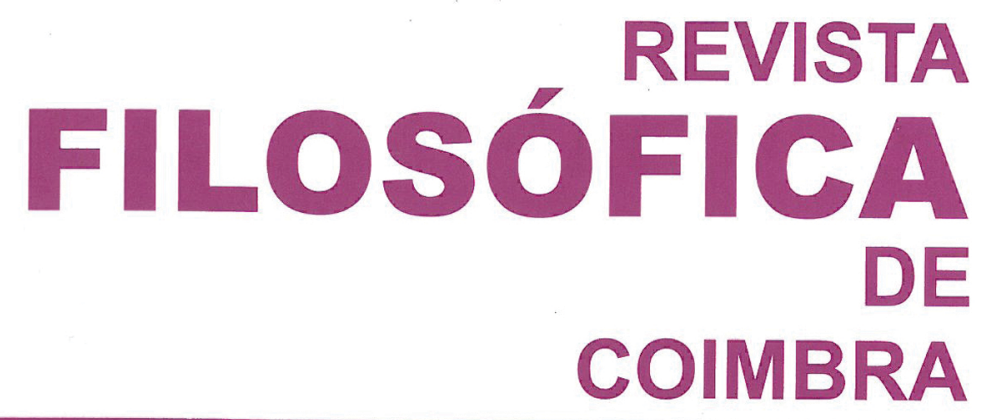

vol. 22 - número 44 - outubro 2013

vol. 22 - número 44 - outubro 2013 Fundação Eng. António de Almeida

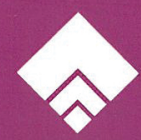




\section{O VISÍVEL E A VISÃO NO MANUSCRITO 2399 ATRIBUÍDO A PEDRO DA FONSECA Nota de investigação sobre o Capítulo VII do Livro II do Comentário ao 'De Anima' de Aristóteles}

MARIA DA CONCEIÇÃO CAMPS*

Resumo: o presente artigo visa dar a conhecer a problemática do visível e da visão ínsita no capítulo VII do Comentário ao De anima de Aristóteles, constante do manuscrito 2399 da Biblioteca Geral da Universidade de Coimbra, atribuído a Pedro da Fonseca. Procura averiguar a existência, ou não, de um possível embrião de uma teoria da visão conimbricense. Para tal, contrasta a doutrina nele inscrita sobre a matéria com a patente no Curso Jesuíta Conimbricense, da autoria de Manuel de Góis. Esta nota de investigação pretende assim, oferecer um contributo para o estudo da génese da doutrina da visão no Colégio de Jesus de Coimbra durante o século XVI.

Palavras-chave: visível, visão, cor, Pedro da Fonseca, Curso Jesuíta Conimbricense.

Abstract: This article aims to apprise the topics of visible and vision on the Chapter VII of the Commentary on Aristotle's De anima, according to the manuscript 2399 of the General Library of the University of Coimbra, attributed to Pedro da Fonseca. It seeks to ascertain the existence, or not, of the rudiments of an original theory of vision in Coimbra. It contrasts its doctrine with that reported in the Coimbra Jesuit Course. This research aims to be a contribution to the study of the genesis of the doctrine of the vision among the Jesuits of Coimbra during the sixteenth century.

Key words: visible, vision, color, Pedro Fonseca, Coimbra Jesuit Course.

* Doutora em Filosofia. Instituto de Filosofia da Faculdade de Letras da Universidade do Porto. 


\section{Sobre a atribuição do manuscrito}

Até hoje ainda não se deu a devida atenção à tradição manuscrita anterior à publicação do Curso Jesuíta Conimbricense ${ }^{1}$. E, no entanto, se nos ativermos apenas ao De Anima, e baseados nas informações de Stegmüller e de Lukács, não só conhecemos os nomes de alguns dos mestres jesuítas, como possuímos três manuscritos anónimos (dois em Lisboa e um no Porto), reveladores do ensino então praticado no Colégio de Jesus de Coimbra. ${ }^{2}$

Sabemos que Inácio Tolosa inicia em setembro de 1564 o De Anima I, que Pedro Luís concluiu em 5 de janeiro de 1568 a lecionação do De Anima II, que em 1590 Pedro Álvares também leciona o mesmo livro (nessa mesma data e no convento Trinitário de Lisboa, Marcos de Moura termina um Comentário ao De Anima) e que em 1591 Cristóvão Gil também ensina o De Anima.

O manuscrito 2399 da Biblioteca Geral da Universidade de Coimbra, atribuído por Stegmüller a Pedro da Fonseca, integra um Comentário ao De Anima de Aristóteles, com 82 fólios $^{3}$. É seguido de um outro texto, desta feita dedicado à Metafisica pese embora a epígrafe se encontre em branco, eventualmente reservada à inscrição de um título que não chegou a ter lugar. Esta última peça é da mão do mesmo calígrafo do texto anterior, situando-se entre o fólio 83 e o fólio 92.

Um apontamento sobre a missa, escrito a uma outra mão, ocupa parte do fólio 92 e estende-se até ao fólio 94. Do mesmo calígrafo que escreveu sobre a missa, regista-se um pequeno apontamento nos fólios 103 e 104.

Evidentemente que não iremos aqui determinar nem resolver o problema da atribuição do manuscrito a Pedro da Fonseca. A proposta de Stegmüller relativa aos dois primeiros livros do De Anima parece-nos plausível pelas razões que passamos a aduzir.

A redação do manuscrito foi iniciada com "incipit" In Primum Aristotelis de Anima Scholia, em 4 de novembro de 1559 e terminada em 27 de janeiro de $1560^{4}$;

1 Sobre o Curso Jesuíta Conimbricense vide Comentários do Colégio Conimbricense da Companhia de Jesus Sobre os Três Livros Da Alma de Aristóteles Estagirita. Introdução Geral à Tradução, Apêndices e Bibliografia de Mário Santiago de Carvalho. Tradução do original latino por Maria da Conceição Camps, Lisboa: Edições Sílabo, 2010.

2 F. Stegmüller, Filosofia e Teologia nas Universidades de Coimbra e Évora no século XVI, Coimbra, Universidade de Coimbra, 1959, passim; LUKÁCS, L. (ed.), Monumenta Paedagogica Societatis Iesu. III: 1557-1572, Romae: Institutum Historicum Societas Iesu, 1974.

3 F. Stegmüller, Filosofia e Teologia, p. 65.

4 Vd. F. Stegmüller, Filosofia e Teologia, p. 65; Ms. 2399, fol. 1r e fol. 82r. 
Sabemos que Pedro da Fonseca ensinou Filosofia nos anos letivos 1555-1561, isto é, um curso completo de Artes ${ }^{5}$. Ora, crendo na possibilidade de o Manuscrito pertencer ao ensino da Companhia de Jesus, além de Pedro da Fonseca os restantes concorrentes jesuítas à autoria do texto seriam Pedro Gómez, Marcos Jorge e Manuel Rodrigues (os dois primeiros foram chamados por Fonseca em 1562 como colaboradores para a futura redação do Curso Jesuíta Conimbricense) ${ }^{6}$.

Ora, presumindo que se terá respeitado o plano de estudos em vigor entre 1552 -1565, o ensino do De Anima deveria ter ocorrido entre o terceiro trimestre do terceiro curso ou o primeiro trimestre do quarto curso. Significativamente, a Metafísica também foi objeto de estudo no mesmo período. ${ }^{7}$

Resulta, portanto, como muito provável que nos anos 1559-1560, Pedro da Fonseca estivesse a reger o último curso e, portanto, a trabalhar sobre o De Anima.

Cremos que Stegmüller poderá ter raciocinado da mesma forma para avançar com a atribuição. Acresce que sabemos, pelo testemunho epistolar do P. Torres, prepósito geral da Província Lusitana, que em fevereiro de 1560 já "uno de los lectores de artes há hecho buena parte de unos ditados en ellas com diligencia para poderse imprimir. (...) Nos ha escrito que dize que haríamos un gran beneficio a esta tierra, si imprimiésemos estos ditados de las artes." $"$

Este testemunho é depois reforçado pelo próprio P. Nadal que, na sequência, atribui essa tarefa a Pedro da Fonseca. ${ }^{9}$

\section{A problemática da visão no Capítulo VII do Livro II do Manuscri- to atribuído a Pedro da Fonseca}

Indo ao encontro do objeto do presente artigo, o vísivel e a visão no Comentário em análise, ele justifica-se quanto a nós, dada a importância deste

${ }^{5}$ F. Rodrigues, História, T. I, vol. II, p.102, nota 2. Sobre a biografia e a obra de Pedro da Fonseca, vd. Joaquim F.Gomes, "Introdução", in Pedro da Fonseca. Instituições Dialéticas. Introdução, estabelecimento do texto, tradução e notas por J. F. Gomes, Coimbra, Universidade de Coimbra, 1964, pp. XXI-LVIII. Para a obra metafísica de Fonseca o melhor título é o de António Martins, Lógica e Ontologia em Pedro da Fonseca, Lisboa: FCG-JNICT, 1994.

6 J.P. Gomes, "Os professores de Filosofia no Colégio das Artes" Revista Portuguesa de Filosofia 11/2 (1955) 524-29; M. S. de Carvalho, "Introdução Geral”, p. 145; L. Lukács, Monumenta Paedagogica Societatis Iesu III, Roma, 1974, p. 318.

7 Vd. M. S. de Carvalho, "Introdução geral", p. 35.

8 Vd. L. Lukács, Monumenta III, p. 317.

9 Ibidem. 
tema para a Companhia de Jesus, mais propriamente para os professores do Colégio de Jesus de Coimbra, em ordem ao cumprimento cabal do seu plano de estudos no que toca ao escopo final que a pedagogia jesuíta coimbrã perseguia - preparar o estudante de Filosofia para os futuros estudos de Teologia, criando pontes entre uma e outra e apostando num tipo de abordagem onde os problemas relacionados com o estudo da alma só poderiam em última instância ser plenamente compreendidos no quadro duma mundividência cristã. A presença de uma metafísica da visão patente no Comentário ao De anima do Curso Jesuíta Conimbricense, é disso exemplo marcante ${ }^{10}$. O percurso nele traçado do visível ao Invisível indicia uma abordagem da visão que ultrapassa a mera perspetiva do fisiólogo, propondo uma ciência da alma repartida entre a Física e a Metafísica, e apontando em última instância para Deus.

O visível, pedra angular de uma doutrina da visão conimbricense, detém à luz do quadro acabado de explanar um estatuto que em muito ultrapassa $o$ proposto por Aristóteles ou mesmo por alguma da melhor tradição dos seus comentadores nos comentários ao De anima e ao De sensu et sensato. Resta-nos questionar se esta originalidade será apenas apanágio do comentário de Manuel de Góis ou se tal doutrina se encontrará disseminada em textos paralelos do Colégio de Jesus. Daí a razão de ser do presente artigo. Será promissora e pertinente a investigação dos restantes manuscritos que integram a tradição jesuíta conimbricense em ordem à obtenção de uma resposta cabal à questão levantada.

Indo diretamente ao encontro do Livro II, Capítulo VII do Comentário ao 'De Anima' de Aristóteles, constante do manuscrito 2399, registamos o seguinte:

Em primeiro lugar, nem este capítulo, nem os restantes, se encontram escritos em forma de comentário, tal como o conhecemos no homólogo do Curso Jesuíta Conimbricense, não obstante o título do mesmo.Também não está organizado em questões onde se encontrem explanadas posições contrárias, nem regista debates acerca das matérias em análise. Antes, foi elaborado segundo a forma de um pequeno tratado onde se expõem as posições doutrinárias do próprio autor, que oferece a sua interpretação de Aristóteles.

No que ao Capítulo VII concerne, dedicado à visão, verificamos que este, embora apresente os temas tratados por Aristóteles no capítulo homólogo da sua obra, se desvia de modo acentuado quer da forma, quer do conteúdo da matéria estudada, já que acaba por integrar posições que o Estagirita incluiu em $O$ Sentido e o Sensivel e noutras obras como Dos Animais e A Geração

10 Para maior desenvolvimento vide $\mathrm{M}^{\mathrm{a}}$ da Conceição Camps, Do visível ao Invisível - A teoria da visão no Comentário aos três livros 'Da alma' do Curso Jesuíta conimbricense ( 1598). Dissertação de doutoramento em Filosofia apresentada à Faculdade de Letras da Universidade do Porto, Porto, 2012. 
e a Corrupção e, como seria de esperar As Cores. Inclui ainda referências a Galeno e à tradição peripatética sobre a matéria e manifesta a influência dos estudos de ótica arábicos, que chegaram até ao ocidente por mão dos Perspetivos, não obstante estes não serem nomeados enquanto tal, mas acolhendo algumas distinções que tiveram origem na tradição da denominada Perspetiva. Nisto não se distancia da maioria das obras da época dedicadas ao assunto, incluindo a de Manuel de Góis, dentro do característico percurso que a melhor tradição aristotélica percorreu até ao século XVI.

O Capítulo VII do manuscrito tem assim, a preocupação de apresentar doutrina sobre a matéria da visão, explicando-a e classificando-a ao jeito do autor, que se solta da organização oferecida pelo texto comentado para desenhar a sua própria leitura e opinião sobre a matéria.

Principia com o elogio da visão, sentido nobilíssimo, não obstante reconhecer que o tacto é o sentido mais necessário à vida. A comparação entre a visão e o tacto remete-nos para o livro de $A$ Geração e a Corrupção, de Aristóteles. ${ }^{11}$

A vista suplanta o tacto não obstante a suprema importância deste, do ponto de vista da sobrevivência estrita do animal. A tangibilidade que o caracteriza é a garantia da relação íntima com a matéria, essencial à vida neste mundo. Já a visão, pelo contrário, não resulta de uma afeção do corpo tangível, sendo superior, em dignidade, ao tacto, por dispensar o contacto físico material em ordem a obter as informações e o conhecimento das coisas. ${ }^{12}$

Após esta introdução, o autor passa de imediato a analisar e a classificar o visível, começando por dividi-lo em três géneros, genus, ${ }^{13}$ que irá tratar, um a um.

Toda a ordenação que o autor do manuscrito atribuído a Pedro da Fonseca faz, subsequentemente, da matéria da visão, encontra-se de algum modo subordinada a esta tríplice partição do visível, relevando a importância central do mesmo em todo o processo visual. O visível é o primeiro grande responsável pelo desencadear da visão.

O primeiro género de visível inclui todo o tipo de cores.

É, quanto a nós, interessante a forma como a definição deste tipo de visível é oferecida. Em lugar da cor simplesmente, ao jeito de Aristóteles e da maioria dos seus comentadores, o autor opta por considerar que o visível colorido integra todo o género de cores. ${ }^{14}$

\footnotetext{
11 Aristóteles, A Geração e a Corrupção II 329 b6.

12 Ms. 2399, fol. 40r- 40 v.

13 Ms. 2399, fol. 40r.

14 Ms. 2399, fol. 40v
} 
O segundo género de visível é uma certa qualidade que aparece nas coisas dotadas de brilho, que são avistadas no escuro. ${ }^{15}$

O terceiro género de visível é uma qualidade do próprio fogo e dos corpos celestes que tanto são vistos de dia, à luz, como de noite, nas trevas. ${ }^{16}$

De realçar esta tríplice classificação, pouco comum entre os comentadores que normalmente oferecem apenas duas, como é o caso de Manuel de Góis ${ }^{17}$, ainda que quase todos discutam as situações inerentes à visão e ao tipo de visível que esta classificação suscita.

O próprio Aristóteles, neste capítulo, apenas apresenta como visíveis a cor e uma certa qualidade que faz com que as coisas sejam avistadas no escuro, o brilho. ${ }^{18}$

Pedro da Fonseca, começa, por isso, a tratar das cores, adiantando que elas atingem a vista devido a algo recebido no ar ou na água, a uma qualidade do meio que atinge a vista. bus. ${ }^{19}$

A propósito das cores e da sua variedade parafraseia o livro De Colori-

Prossegue com a definição de cor como qualidade existente na superfície dos corpos determinados. Remetendo para $O$ Sentido e o Sensivel, afirma que a cor é a transparência num corpo determinado. ${ }^{20}$ Todos os corpos beneficiam da transparência, uns mais, outros menos. Esta qualidade é comum aos corpos celestes e aos sublunares. ${ }^{21}$

Os elementos também possuem a qualidade da transparência como o fogo, o ar, a água e a terra, embora este último elemento a tenha muito pouco acentuada. Nesta qualidade da transparência se irá manifestar a cor. Ela é evidente na superfície dos corpos determinados, já que nestes corpos a mistura dos elementos mais ou menos transparentes produz a variedade das cores, que vão alterando os seus matizes entre as cores extremas, o branco e o negro. 22

A mistura de branco e de negro e do respetivo diáfano estará na origem da variedade das cores. ${ }^{23}$

Mas a cor requer a luz para que possa manifestar-se e desencadear a visão. Daí a necessidade da atualização do diáfano. A espécie ou imagem

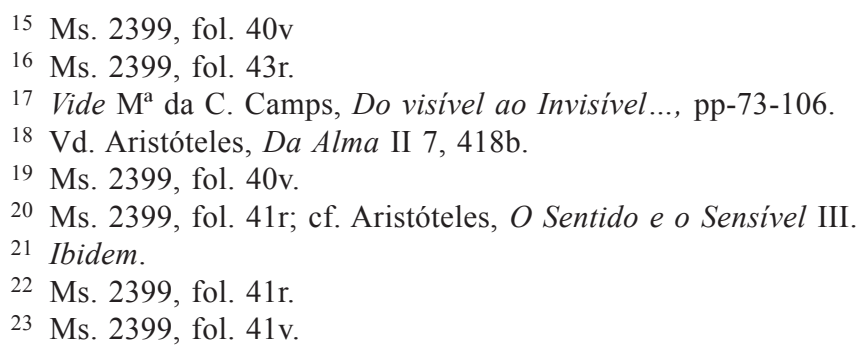


da cor é uma qualidade espiritual dada a sua incorporeidade. A luz, lumen, manifesta a cor, uma qualidade espiritual dado ser intencional e não real. ${ }^{24}$

$\mathrm{O}$ autor passa a distinguir um outro tipo de cores, para além daquelas que estão presentes nos corpos determinados, a saber, as meteorológicas e as que resultam da mistura da luz e das trevas. Estas cores aparecem nas nuvens, no céu, no arco-íris, nas coroas e noutros fenómenos atmosféricos, sendo passageiras, ao contrário das que subsistem como mistura fixa de elementos portadores de uma transparência invariável. O primeiro género de cores, permanentes, permanentes. ${ }^{25}$ Estas cores não são mais do que transparência, mais ou menos misturada, nos corpos singulares. As outras, são luz, lumen, alterando-se rapidamente porque a lumen é um efeito da luz, lux, que os corpos transparentes recebem. Resultam, pois, do reflexo da luz que ao incidir nestes corpos origina cores variadas e transitórias, transeuntes. ${ }^{26}$

Adianta ainda que a luz enquanto cor é um sensível, mas enquanto meio é uma qualidade insensível, insensibilis. A lumen enquanto imagem da lux é espiritual e insensível (qualitates insensibiles). ${ }^{27}$

Depois de tratar o visível que é composto por todo o tipo de cores passa a explicar em que é que ele consiste.

O segundo género, genus, de visível é portador de uma qualidade intermédia e comum entre a transparencia e a lux que faz com que os corpos que a contêm sejam avistados no escuro, com uma espécie de luz. São vistos de noite, no escuro, mas não de dia. Exemplos de corpos portadores desta qualidade são os carvalhos velhos, os olhos dos felinos, de entre outros. ${ }^{28}$

$\mathrm{O}$ terceiro género de visivel consiste num certo tipo de brilho, splendor, que é avistado no fogo ou nos corpos celestes. Esta qualidade permite que os corpos sejam avistados de dia e de noite, na luz e na escuridão e, nos corpos luminosos, é uma espécie de cor. ${ }^{29}$

Uma vez classificados os visíveis, passa a debruçar-se sobre a composição dos olhos procedendo à sua descrição, citando Galeno e Aristóteles e explica também que os olhos contêm água para poderem receber as cores. ${ }^{30}$

$\mathrm{O}$ manuscrito termina com alguns esclarecimentos relativos à luz e às suas variantes, numa clara aportação da perspetiva.

A lumen é o efeito da luz, lux, que é recebida nos corpos transparentes.

\footnotetext{
24 Ms. 2399, fol. 42r.

25 Ms. 2399, fol. 42v.

26 Ms. 2399, fol. 42r- 42v.

27 Ms. 2399, fol. 42r.

28 Ms. 2399, fol. 42v.

29 Ms. 2399, fol. 43r.

30 Ms. 2399, fol. 43r- 43v.
} 
A luz é a qualidade que reside nos corpos luminosos, lucidis, e pertence à terceira espécie de qualidade de alguns visíveis, como o fogo, o Sol.

Se a lumen se produz em linha reta, toma o nome de raio, radius. Se é produzida por efeito da reflexão toma o nome de splendor, brilho. Os corpos opacos não recebem lux ou lumen. A cor é um efeito da luz e da transparência. $^{31}$

Não nos alongaremos mais na análise do presente manuscrito que necessita de um tratamento profundo, designadamente de ser transcrito, em ordem a um melhor acesso ao texto, incluindo a possibilidade de publicação.

Insitiremos apenas nalguns pontos que consideramos fulcrais em ordem à compreensão do ensino no Colégio de Jesus de Coimbra sobre o capítulo da visão.

\section{Apreciação doutrinal}

É significativa a ênfase que o manuscrito atribuído a Pedro da Fonseca coloca na tripartição do género de corpos visíveis, para melhor compreensão do fenómeno da visibilidade, ao acentuar o papel fulcral do visível e do meio em todo o processo da visão.

Como vimos na dissertação atrás citada. o mesmo sucederá com Manuel de Góis que, não obstante dedicar mais páginas do seu Comentário homólogo à descrição dos mecanismos da visão, designadamente sobre o aparelho ocular e a visão em espelhos, que o presente manuscrito não refere, constitui como cerne da teoria da visão, o visível e as respetivas relações com o meio.

De realçar a originalidade de Pedro da Fonseca que, para sublinhar a invisibilidade, acentua aquilo que apelida de qualidade insensível, ou seja, aquela que não pode ser vista só por si, como diria Aristóteles, mas pela cor alheia, já que é uma qualidade invisível e, portanto, insuscetível de mover o sensível. A transparência como forma de invisibilidade, de meio, onde se manifesta a cor está patente na descrição do primeiro género de visível.

Manuel de Góis não regista a existência deste termo, insensível, pese embora alcancemos um sentido comum a ambos os autores no que diz respeito à manifestação das cores no diáfano.

Também a tripartição do visível não preocupa Manuel de Góis que segue Aristóteles na bipartição do mesmo.

É evidente que as coisas possuidoras de luz própria, lux, estão elencadas no Comentário de Manuel de Góis, mas a classificação de Pedro da Fonseca parece-nos mais rigorosa do ponto de vista sistemático e mais produtiva, já que abre de imediato caminho para a distinção entre lux, lumen, splen-

31 Ms. 2399, fol. 44r-44v. 
dor e radius, incluindo-as na própria definição dos géneros de visível. Tal é enjeitado por Manuel de Góis no Comentário Da Alma e remetido para o Comentário a $O$ Céu.

A possibilidade que o texto de Fonseca oferece ao casar a herança perspetiva com o acervo aristotélico nesta matéria, permite-nos um rigor na classificação que nem sempre está tão presente no Comentário de Manuel de Góis, designadamente quando o primeiro faz depender as cores passageiras da lumen e os próprios corpos que são avistados no escuro mas não à luz, respetivamente primeiro e segundo género de visível.

Já as tipologias das cores, verdadeiras e falsas para Manuel de Góis, permanentes e passageiras para Pedro da Fonseca, também nos questionam acerca da bondade dos respetivos critérios.

Efetivamente, para Pedro da Fonseca é inquestionável, e decorre da própria classificação, que todas as cores são verdadeiras. O primeiro género de visível refere todo o tipo de cores, permanentes e passageiras, como cores. A única diferença reside na natureza de ambas.

Aqui encontramos uma convergência com Manuel de Góis. Na realidade quer para um quer para outro, as cores passageiras/falsas são lumen. As cores permanentes/verdadeiras resultam da mistura dos elementos e das suas qualidades.

No entanto, Manuel de Góis apelida de falsas ou fictícias as cores que segundo Pedro da Fonseca são inelutavelmente verdadeiras, ainda que passageiras, porque se comportam como um sensível do género da cor, um visível do primeiro género enunciado no Comentário.

De realçar também a preocupação de Pedro da Fonseca em registar a transparência como qualidade existente em todos os corpos e em sublinhar que é ela que permite a manifestação da visibilidade, sugerindo uma dialética visível/invisível que muito nos apraz registar, dado que denota a importância do binómio que realçámos supra como cerne da teoria da visão do Curso Jesuíta Conimbricense ${ }^{32}$.

\section{Conclusão}

Encontrámos neste manuscrito aquilo que poderemos apelidar de antepassado próximo da teoria da visão do Curso Jesuíta Conimbricense. De algum modo, já se patenteia em 1559-1560, um núcleo doutrinário caracterizador do pensamento dos jesuítas de Coimbra sobre esta matéria.

Esta unidade doutrinal, não obstante as diferenças de abordagem é um assunto a investigar, quiçá muito promissor, assim se transcreva e estude

32 Vide $\mathrm{M}^{\mathrm{a}}$ da C. Camps, Do visivel ao Invisivel..., pp. 217-227. 
todo o acervo de manuscritos que existem sobre a matéria e que ainda se encontram por trazer à luz.

O embrião de uma tipologia das cores do Curso Jesuíta Conimbricense, teoria cuja reconhecida produtividade sublinhámos noutro lugar, quando abordámos a teoria das cores de Goethe ${ }^{33}$, já encontra raízes neste manuscrito, remetendo para um thesaurus doutrinal que urge desbravar e dar a conhecer, não só nesta sede como em todas as matérias concernentes à filosofia que se fazia no tempo e no lugar.

33 Vide $\mathrm{M}^{\mathrm{a}}$ da C. Camps, Do visível ao Invisivel..., pp. 91-97. 